\title{
Information and Education Systems in the Context of Digitalization of Education
}

\author{
Sergey D. Karakozov ${ }^{\mathrm{a}}$ and Natalia I. Ryzhova ${ }^{\mathrm{b} *}$ \\ anstitute of Mathematics and Informatics \\ Moscow State Pedagogical University \\ 1/1 M. Pirogovskaya Str., Moscow, 119991, Russia \\ ${ }^{b}$ Institute of Education Management \\ of the Russian Academy of Education \\ 16 Zhukovskogo Str., Moscow, 105062, Russia
}

Received 31.07.2019, received in revised form 26.08.2019, accepted 09.09.2019

The article describes the changes in the modern socio-economic environment, which affect the digitalization of society, including the socio-educational sphere. On the basis of the authors' proposals for the development of the concept of "information-educational systems", mathematical models for their description and mechanisms for analysing their essential characteristics determined by modern processes of development and digitalization of society are indicated. Through the example of using elements of the theory of dynamic deductive databases and the theory of neural networks, the article describes mathematical models that adequately reflect strategies for the development of people and stable small groups, as well as large dynamic human communities, on the basis of which recommendations are proposed for developing such strategies. The results can be used in the pedagogical design of various models of educational activities and information and educational systems for various purposes, including education management and direct training. It also seems that the mechanisms and features of information and educational systems described in the article will allow us to establish an evidence-based educational policy at various levels in the context of digitalization.

Keywords: educational policy, education system development strategy, digitalization of society and education, information and education systems, mathematical models and mechanisms, information models, dynamic deductive databases, neural networks.

Research area: pedagogy; psychology; computer science, computer engineering and management.

Citation: Karakozov, S.D., Ryzhova, N.I. (2019). Information and education systems in the context of digitalization of education. J. Sib. Fed. Univ. Humanit. soc. sci., 12(9), 1635-1647. DOI: $10.17516 / 1997-1370-0485$.

(C) Siberian Federal University. All rights reserved

* Corresponding author E-mail address: nata-rizhova@mail.ru

ORCID: 0000-0002-5868-8157 (Ryzhova); 0000-0002-6902-3150 (Karakozov)

This work is licensed under a Creative Commons Attribution-NonCommercial 4.0 International License (CC BY-NC 4.0). 


\section{Introduction}

Modern philosophers, in particular, Z. Sardar (1997) believe that we live in a postnormal time - an intermediate period when old traditions have already become obsolete and new ones have not yet taken root. In this transitional era, human and natural systems often come close to a chaotic state. In such cases, we say that systems become "postnormal," which means, they cease to show their usual characteristics. Supporters of postnormality characterize modernity with the help of three $C$ Chaos, $\boldsymbol{C}$ omplexity, Contradictions. In turn, this allows us to distinguish the following characteristics of modern society: (1) acceleration of changes, (2) connectedness of everything and with everything, and (3) globalization of space.

In another work, Z. Sardar notes that the current state of society corresponds to: uncertainty, rapid changes, redistribution of power, protest and chaotic behavior: "We live in an intermediate period when the old orthodoxy is dying and the new one has not yet been born and has little meaning. Our time is transitive, a time without confidence that we can return to any past known to us, and without confidence that any way can lead us to a desired, attainable and sustainable future" (Sardar, 2010: 435-444).

One of the possible approaches to normalizing the existence of modern society is its digitalization followed by the analysis of the resulting "digital shadow" by means and methods of "big data" and the development of recommendations for achieving social stabilization (ideally, achieving homeostasis) for a particular system, including modern society.

Thus, modern society is entering a new stage in its socio-economic development, which is commonly called "digital economy" or simply "digitalization." As part of this stage, there is global digitalization of all aspects of human life, including the socioeducational sphere. The main essential characteristic of "digitalization of education" in this case is the use of digital educational resources and information and educational systems to solve various professional tasks of employees in the educational system managers, educators and teachers (Karakozov, Mitrofanov, 2011; Karakozov, Ryzhova, 2016; Lubkov, Karakozov, Ryzhova, 2017; Uvarov, Karakozov, Ryzhova, 2018; Smolianinova, Popova, 2019; Smolianinova, Ovchinnikov, 2012; Smolianinova, Shilina, 2011).

For the first time on a global scale, the movement towards the digital economy was announced in 2016, when the UN Ministerial Declaration on the Digital Economy: Innovation, Growth and Social Well-being was adopted at the UN Ministerial Conference in Cancun (Mexico) (Ministerial, 2019). Let us note that it was in this 
document that the main objectives of the development of the digital economy were formulated for the first time, and the need to develop global technical standards that ensure the compatibility and security of technologies based on open access to the global Internet was also emphasized.

In Russia, the transition to the digital economy was announced in the annual message of the President of the Russian Federation V. V. Putin, when speaking to the Federal Assembly of the Russian Federation he suggested "launching a large-scale systemic program for developing the economy of a new technological generation, the so-called digital economy" (Poslanie..., 2019).

In this article, based on our works summarized in a monograph (Karakozov, Ryzhova, 2017), we will single out information-mathematical approaches and mechanisms for describing the development and analysis of educational processes in modern conditions, in particular, digitalization of society.

\section{Theoretical framework}

Today, one can ascertain the existence of a multitude of definitions of concepts and terms related to information systems that, to one degree or another, are designed to describe modern society and its socio-educational sphere. In this regard, to form our view of understanding a number of basic terms in this field and to use them, for example, in the pedagogical design of information and educational systems in the context of digitalization of the social and educational sphere, we will try to choose the most common and most interesting tasks closest to the context, including the description of the concept of information and educational systems.

When writing this article, we will mainly rely on the works of M. R. Kagalovskii (Kagalovskii, 2003), S. P. Rastorguev (Rastorguev, 1999; 2014) as the closest to us in understanding the essence of the issues we are interested in, as well as related section of our monograph (Karakozov, Ryzhova, 2017: 130-166).

Let us turn to the understanding of the term "system" that has many definitions, but each of them implies the unity of the laws of movement (in the sense of development) of the elements that make up this system. Thus, by a system we mean a totality of abstract or material objects together with known or given connections and relations that form a single whole in a known (or given) sense.

An information system is a system that implements: receiving input data; processing this data and/or changing its internal state (internal connections/relations); resulting or a changing in their external state (external connections/relations). 
There are various approaches to the classification of information systems. For the purposes of our study, we will consider a classification based on the mathematical models used in their construction. We will distinguish between simple and complex information systems:

- A simple information system is a system the elements of which function in accordance with the rules generated by the same, mutually consistent set of axioms.

- A complex information system is a system that contains elements that operate in accordance with the rules generated by different sets of axioms. Moreover, it is assumed that among the rules for the functioning of various elements there may be conflicting rules and goals.

Violations in the interaction of elements of a complex system with each other leads to the reprogramming of these elements and/or their destruction. Thus, the protocols of information-logical conjugation of the elements of a complex system, means and technologies of their practical implementation are very important in understanding the nature of information systems.

The protocol of the information-logical interaction for the elements of social space is embodied in a natural language. The use of one or another linguistic subset of a language largely determines the information capabilities of various population groups.

Depending on what changes occur in the internal state of information systems, S.P. Rastorguev (Rastorguev, 2014) proposed distinguishing information systems of two classes: class A - systems with an unchanged internal state and class B systems with a changing internal state.

In turn, in class B it is possible to distinguish the following subclasses:

- subclass 1 - systems with a constant processing algorithm, but with changing data that are used in the processing of input information;

- subclass 2 - systems with an adaptive processing algorithm, in which the algorithm is adjusted to the conditions of its application;

- subclass 3 - systems with a self-modifying goal and, accordingly, with a fully self-modifying algorithm that goes beyond a set of equivalent algorithms.

Systems of the subclass 3 will be called self-learning.

An informational self-learning system is required to constantly maintain its own correspondence to the surrounding (accordingly, changing) environment. Maintaining conformity means changing (learning). Thus, the classification of information systems in this work is based on internal, initially inherent abilities to maintain this correspondence. 
The same can be said about automated information retrieval systems; depending on the implementation, they can be assigned to systems of both subclass 1 and subclass 2 .

Further, let us dwell on the formal definitions of the description of the information model used in the framework of the information system.

A business model is a description of a managed object as a complex system, with some given accuracy. Within the business model, all objects (entities), processes, rules for performing operations, the existing development strategy, as well as criteria for evaluating the effectiveness of the functioning of the system are represented. A form of presentation of the business model and its level of detalization are determined by the modelling goals and the accepted point of view of a user of the information system.

An information model is a subset of a business model that describes existing (including non-formalized in a documentary form) information flows, processing rules and routing algorithms for all elements of the information field.

Following M. R. Kagalovskii (Kagalovskii, 2003), we propose the following definition of an information system: "An information system is a complex that includes computing and communication equipment, software and system personnel that provide support for a dynamic (time-dependent) information model of a certain application environment for satisfying the information needs of a certain group of users" (Karakozov, Ryzhova, 2017: 134-135).

Based on the above definitions of the basic concepts of information systems, we will understand the information and educational system as a complex that includes computing and communication equipment, software and system personnel providing support for a dynamic (time-dependent) information-mathematical model of the education system to meet the information needs of an individual, society and state.

\section{Statement of the problem}

As follows from the foregoing, the information system is designed to record the state of an object at a given point in time. A sequence of such states is a sequence of system states, which allows us to interpret the information model used by the system as a discrete dynamic system. And this, in turn, allows us to use specific mathematical methods to analyse its possible states. Their totality and sequence of use allow us to obtain results regarding the objects by analysing the state of the system by correlating real social objects with their information models. A detailed study of these issues can be 
found in the work of Iu. M. Plotinskii (Plotinskii, 2001); A. K. Guts, V. V. Korobitsyn, A. A. Laptev, L. A. Pautova, Iu. V. Frolova (Guts et al., 2000; Korobitsyn, Frolova, 2003).

One of the possible and priority areas of the use of mathematical methods in humanitarian research in our study is the modeling of the processes of the studied application environment or professional sphere by analysis methods by means of logical programming of discrete dynamic systems (Dekhtiar, 2009; Dekhtiar, Dikovskii, 1996).

Let us note that one of the pioneers of their use in modelling social systems is S.P. Rastorguev (1999), who also showed that, along with logical programming methods, an equivalent tool for analysing and studying such processes or phenomena is the neural network modelling mechanism, which is the basis for the theory of neural networks (Gurney, 1997; Haykin, 1999).

Let us consider what issues are being studied in the framework of these approaches. The classical theory of algorithms dealt mainly with the classification of algorithmic problems into decidable and unsolvable, focusing on the latter. The theory of complexity of algorithms and calculations, which occurred in the 60 's of the $20^{\text {th }}$ century, focused on the classification and study of the complexity of solvable problems (Harel, 2004). It is these questions regarding the models constructed in the work that we are considering.

In addition, this approach, based on the development of models of discrete dynamic systems and the use of logical programming methods, allows us to analyse the stable behaviour of such systems in interaction with the external environment.

\section{Methods}

In order to study and analyse the behaviour of educational processes and systems in modern conditions of digitalization, we propose to correlate various types of similar systems with mathematical objects of different types, primarily neural networks of a certain type (dynamic deductive databases) and to study the behaviour of such objects by means of the theory of discrete dynamic systems. Using this approach, it is possible to construct a theory of the behaviour of information models of educational systems of various types based on the mathematical theory of neural systems or, equivalently, on the theory of deductive logical systems. In particular, within the framework of this approach, it is possible to analyse the sustainable behaviour of information and educational systems in interaction with the external environment. 


\section{Discussion}

Next, we will consider some common features for the classification and analysis of specific natural properties of the stable behaviour of discrete dynamic systems, the states of which, as a rule, can be described using a finite number of relations on values of the system parameters.

In our analysis, we proceed from the fact that the states of the system are divided into acceptable and unacceptable (states in which the system cannot function properly). The interactive nature of the behaviour of the systems we are considering implies the existence of an active external environment, and the system functions in the interaction with it. The effect of the external environment on the states of the system is represented using a separate binary relation, which we will call a perturbation.

With this approach, the fundamental difference between the system and the external environment is determined by the level of our knowledge about them. It is assumed that the theory that defines the behaviour of the system completely familiar. As for the external environment, it is non-deterministic - it is only known how to determine the result of applying a specific perturbation to the state of the system. At the same time, it is impossible for the current state to accurately predict which of the possible perturbations will be applied to it.

In these terms, the evolution of a discrete system can be represented as a finite or infinite trajectory consisting of its actions and perturbations of the external environment.

For educational information systems, in our opinion, it is advisable to consider three types of "survivability properties" (stability) of a discrete dynamic system.

1. In the first case, the trajectory begins in an unacceptable state and the system, together with the external environment, finally achieves the acceptable state. In this case, the initial state is called promising.

2. In the second case, the trajectory begins in an acceptable state and the first action is performed by the system. Its actions can lead to unacceptable states, which are transformed into acceptable ones by perturbations in the external environment. Such trajectories are called stable.

3. In the third case, the trajectory starts in an acceptable state, to which the perturbation of the external environment is applied. If the acceptability is violated, the system must restore it as a result of its action. Such trajectories are called homeostatic.

From a mathematical point of view, the perspectivity property is closely related to the planning problem that is well known in artificial intelligence, which can be 
formulated as the problem of the existence of a plan (trajectory) that brings the system to a given state or to a state that satisfies certain predetermined conditions.

The meaning of the other two definitions is as follows. In the homeostatic trajectory, the system is able to regularly restore its state (some property) in response to perturbations of the environment that destroy it. Accordingly, along a stable trajectory, the actions of the environment compensate for the possible destructive actions of the system.

In our work, we confine ourselves to analyses of the first case (perspectivity of trajectories). We have left the analysis of the second and third cases for the following works.

Let us turn to a number of definitions of the basic concepts of the theory of neural networks and the classification of self-learning systems built on their basis, through:

- changes in relations between elements;

- changes in functional possibilities of the elements themselves;

- changes in the number of elements: elements can be born and die.

Artificial neural networks are mathematical models, as well as their software or hardware implementations (information systems), built on the principle of the organization and functioning of biological neural networks, which are a system of connected and interacting artificial neurons that exchange information.

An information self-learning system is an artificial neural network, the behaviour of which undergoes changes under the influence of information. Typically, classification of such systems is carried out according to the type of the digestion of information:

1. Neural networks as a model of the informational self-learning system - a model in which the digestion of information occurs by changing relations;

2. R-networks as a model of the informational self-learning system - a model in which the digestion of information occurs by changing relations between the elements and the destruction of the elements of the system;

3. S-networks as a model of the informational self-learning system - a model in which the digestion of information occurs by changing relations between the elements and self-generation of the system elements;

4. SR-networks as a model of the self-learning information system - a model in which the digestion of information occurs due to all possible ways of changing the structure (changing connections, self-generation and death of elements).

As an example, let us point out that the learning processes of an individual person are more adequate for the processes occurring in R-networks, while the possibilities and learning processes of human communities are more convenient to model using 
S-networks for small, stable communities (various kinds of connections arise between people, a community obtain a small number of new members) and SR-networks for dynamic communities significant in the number of elements (various kinds of connections arise between people, they enter and exit existing communities).

Let us provide statements of theorems regarding the properties of mathematical models that underlie the study of the behaviour of dynamic systems, which, in our opinion, should be used to study the behaviour, development and analysis of the states of information and educational systems in digitalization, and based on which informative conclusions about the behaviour of such systems will be made.

A theorem on R-network capabilities was proposed by S. P. Rastorguev (Rastorguev, 2014). A self-learning information system based on the principles of the R-network can be trained to solve any problem if and only if the following two conditions are fulfilled:

1) the information capacity of the R-network (the initial number of elements and connections between them) is sufficient to store the incoming information;

2) the initial state of the R-network can be characterized as a state with uniformly distributed connections, i. e. the initial state of the R-network is chaos.

A theorem on the S-network capabilities was proposed by S.P. Rastorguev (Rastorguev, 2014). A self-learning information system based on the principles of the S-network can be trained to solve any problem if and only if the following two conditions are fulfilled:

1) the information capacity of the S-network (the initial number of elements and the connections between them) is sufficient to store the incoming information;

2) the initial state of the S-network can be characterized as a state with uniformly distributed connections, i. e. the initial state of the S-network is chaos.

A theorem on the SR-network capabilities was proved by M.I. Dekhtiar and A. Ia. Dikovskii (Dekhtiar and Dikovskii, 1996). The problem of training a self-learning information system built on the principles of a SR-network to solve the problem of transferring system elements to an arbitrary acceptable state, even if the information capacity of the SR-network (the initial number of elements) is sufficient to store the incoming information, is algorithmically unsolvable.

\section{Conclusion/Results}

The above definitions and mathematical models, as well as theorems regarding the distinguished classes of neural networks that define the internal structure of information and educational systems, allow us to draw the following conclusions. 
For information and educational systems modelled by R-networks, if the conditions specified in the theorem are fulfilled (in case the necessary network information capacity is available):

a) The R-network can be trained to solve any problem (brought into any acceptable state).

b) The R-network cannot perceive new knowledge, which rejects the truth of already formed rules.

c) The R-network rules can only be adjusted within the framework of the redundancy remaining in the system.

Since the education strategy for a man is modelled by the R-network, the strategy of continuous training must take these principles into account. In particular, from these principles it follows that methods, since they are more universal, should prevail over dogmas, the possibilities of education are not unlimited, and therefore, the curriculum at the initial stages of training should not be overloaded.

As for the strategy of activity of stable small groups, which is modelled by the S-network, the mathematical results presented with respect to S-networks suggest that, if the conditions specified in the theorem are fulfilled, successful activity and development of such groups can be ensured by introducing new members into the group - "provocateurs" and training courses aimed at the destruction of prevailing stereotypes of activity.

Since the society (large communities) management strategy, both one's own (civilizational development) and competing one (information warfare), is described by the SR-networks, the mathematical results presented regarding the SR-networks allow us to draw the following conclusions - there is no general solution to this type of problem. In particular, a universal criterion for choosing the best development path is impossible. In the case of the education system, for example, it is necessary to take into account not only the external conditions and directions of the development of society, but also the psychophysiological characteristics of the population, and possibly its historical traditions. So, traditionally, the Russian system of higher education was guided by the German model, which led mainly to fairly high results. In our opinion, a universal solution to this problem does not exist and it is not entirely clear that the Anglo-Saxon system, which is currently being introduced, will provide better results for Russian education.

To summarize the above, let us note that the above understanding of information and educational systems in the context of modern changes and digitalization, their 
essential characteristics, as well as the proposed information and mathematical models will allow the efficient use of such systems for modelling educational strategies at different levels.

\section{References}

Dekhtiar, M.I. (2009). Semantika i analiz slozhnosti algoritmicheskikh problem dinamicheskikh sistem i iazykov, ispol'zuiushikh logicheskoe programmirovanie: avtoreferat doktorskoi dissertacii [Semantics and complexity analysis of algorithmic problems of dynamic systems and languages using logical programming: abstract of doctoral dissertation], Pereslavl-Zalessky, Izd-vo Tverskoi gosudarstvennyi universitet, $35 \mathrm{p}$.

Dekhtiar, M.I., Dikovskii, A. Ia. (1996). Analiz povedeniia diskretnykh dinamicheskikh sistem sredstvami logicheckogo programmirovaniia [Analysis of the behaviour of discrete dynamic systems by means of logical programming]. In Programmirovanie [Programming], 3, 3-16.

Harel, D. (2004). Algorithmics: the spirit of computing. 3rd ed. Pearson Education Ltd., 536.

Haykin, Simon S. (1999). Neural networks: a comprehensive foundation. Prentice Hall.

Gurney, Kevin (1997). An introduction to neural networks. UCL Press.

Guts, A.K., Korobitsyn, V.V., Laptev, A.A., Pautova, L.A., Frolova, Iu.V. (2000). Matematicheskie modeli sotsial'nykh sistem [Mathematical models of social systems], Omsk, Omsk State University, 256 p.

Kagalovskii, M.R. (2003). Perspektivnye tekhnologii informatsionnykh system [Advanced technologies of information systems], Moscow, DMK Press, Kompaniia AiTi, 288 p.

Karakozov, S.D., Mitrofanov, K.G. (2011). Setevaia organizatsiia obrazovaniia: tendentsii i perspektivy [Network organization of education: trends and prospects]. In Mir nauki, kul'tury, obrazovaniia [World of science, culture, education], 4 (1), 180-182.

Karakozov, S.D., Ryzhova, N.I. (2016). Obespechenie stabil'nosti i razvitiia obrazovatel'nykh sistem v usloviiakh transformatsii tsennostei [Ensuring stability and development of education systems in the conditions of transformation of values]. In Prepodavatel' 21 vek [Teacher of the 21 st century], 4 (2), 15-27.

Karakozov, S.D., Ryzhova, N.I. (2017). Teoriia razvitiia i praktika realizatsii soderzhaniia obucheniia $v$ oblasti informatsionno-obrazovatel'nykh system [Theory of 
development and practice of implementation of the content of education in the field of information and education systems]. Moscow, MPGU, 392 p.

Korobitsyn, V.V., Frolova, J.V. (2003). Mathematical Modelling the Ethnic System. In Lecture Notes in Computer Science, 2658, 629-635. (Springer-Verlag Heidelberg, 2003).

Lubkov, A.V., Karakozov, S.D., Ryzhova, N.I. (2017). Tendentsii razvitiia sovremennogo obrazovaniia $\mathrm{v}$ usloviiakh stanovleniia tsifrovoi ekonomiki [Trends in the development of modern education in the conditions of the digital economy]. Mezhdunarodnaia nauchno-prakticheskaia konferentsiia "Informatizatsiia obrazovaniia: teoriia i praktika” [International scientific and practical conference "Informatization of education: theory and practice" 18-19 November 2017 g.], Omsk, 41-47.

Ministerial declaration on the digital economy: innovation, growth and social prosperity (“Cancún declaration”), Available at: http://www.oecd.org/sti/ieconomy/ Digital-Economy-Ministerial-Declaration-2016.pdf (accessed 25 June 2019).

Poslanie prezidenta federal'nomu sobraniiu [Message from the President to the Federal Assembly], Available at: http://www.kremlin.ru/events/president/news/53379 (accessed 25 June 2019).

Plotinskii, Iu.M. (2001). Modeli sotsial'nykh protsessov [Models of social processes]. Moscow, Logos, 296 p.

Rastorguev, S.P. (1999). Filosofiia informatsionnoi voiny [The philosophy of information warfare]. Moscow, Radio i sviaz', 416 p.

Rastorguev, S.P. (2014). Matematicheskie modeli v informatsionnom protivoborstve [Mathematical models in information warfare]. Moscow, CSOiP, 270 p.

Sardar, Z. (1997). Postmodernism and the Other: New Imperialism of Western Culture, Pluto Press, London, 344.

Sardar, Z. (2010). Welcome to Postnormal Times. In Futures, 42, 435-444.

Smolianinova, O.G., Shilina, N.G. (2011). E-portfolio in Higher Educational Institutions of Russia. In Information technology interfaces, Zagreb: University of Zagreb, 331-337, available at: https://ieeexplore.ieee.org/document/5974044

Smolyaninova, O.G., Popova, J.V. (2019). Specific issues of training intercultural mediators for education in Europe and Russia. In J. Sib. Fed. Univ. Humanit. soc. sci., 12(2), 247-260. DOI: 10.17516/1997-1370-0392.

Smolianinova, O.G., Ovchinnikov, V.V. (2010) The strategy of implementing e-portfolio in training elementary teachers within the constructive learning paradigm, 
In Proceedings of the 9th European Conference on e-Learning Instituto Superior de Engenharia do Porto, (2), 828-836. Available at: https://link.springer.com/ chapter/10.1007 \%2F978-3-642-25908-1_43

Uvarov, A.J., Karakozov, S.D., Ryzhova, N.I. (2018). Na puti k modeli tsifrovoi shkoly [Towards a digital school model]. In Informatika i obrazovanie [Computer science and education], 7, 4-15.

\title{
Информационно-образовательные системы в контексте цифровизации образования
}

\author{
С. Д. Каракозов ${ }^{\mathbf{a}}$, Н.И. Рыжова \\ ${ }^{a}$ Институт математики и информатики \\ Московский педагогчческий государственный университет \\ Россия, 119991, Москва, ул. Малая Пироговская, 1/1 \\ ${ }^{\circ}$ Институт управления образованием \\ Российской академии образования \\ Россия, 105062, Москва, ул. Жуковского, 16
}

В работе описаны изменения современной социально-экономической среды, влияющие на ииифровизачию общества, в том числе и на сочиально-образовательную сферу. На основе предложений авторов по развитию понятия «информационно-образовательные системы» указываются математические модели описания таких изменений и механизмы анализа их сущностных характеристик, определяемых современными процессами развития и цุифровизащии общества. В работе на примере использования элементов теории динамических дедуктивных баз данных и теории нейронных сетей указаны математические модели, адекватно отображающие стратегии развития человека и устойчивых малых групп, а также больших динамических человеческих сообществ, на основе чего предложены рекомендащии по разработке подобных стратегий. Полученные результаты могут найти применение в педагогическом проектировании моделей образовательной деятельности и информационно-образовательных систем различного назначения, включая и управление образованием, и непосредственно обучение. Представляется также, что описанные в статье механизмы и особенности информационно-образовательных систем позволят перейти к построению доказательной образовательной политики разного уровня в условиях циифровизации.

Ключевые слова: образовательная политика, стратегия развития системы образования, ичифровизация общества и образования, информационно-образовательные системы, математические модели и механизмы, информационные модели, динамические дедуктивные базы данных, нейронные сети.

Научная специальность: 13.00.00 - педагогические науки; 19.00.00 - психологические науки; 05.13.00 - информатика, вычислительная техника и управление. 